were running the commission, gaining more respect, becoming more integrated into astronomy as a whole, and joining other IAU Commissions. They never did feel compelled to form their own societies or journals, or to have to choose between unions. In fact, the IAU and URSI worked closely together, as in a joint committee appointed to pass judgment on the reliabiliy of alleged radio-sources - in the final list of 1955 only eight (!) were classified as "most certainly existing" (meaning have a good optical identification). By the end of the postwar decade radio astronomers adopted the policy of supporting both URSI and IAU (even as they do today) with results of techniques and the atmosphere tending to be given at URSI meetings and those of astronomy at IAU meetings.

\title{
Discussion
}

D. Jones : I was a student in the mid 50s and remember that Cambridge University appointed Martin Ryle 'professor of Radio Astronomy' which indicates that the term had already achieved respectability by that time. At the same time Woolley started his annual series of conferences at Herstmonceux to which all UK and many overseas astronomers were invited. The only conflict I can remember was minimal and was between the Cambridge and Manchester Radio Astronomy groups.

W.T. Sullivan : My talk was focussed on the postwar decade, and indeed by the end of that decade (1955) radio astronomers were a far more integrated part of astronomy than in the late 1940 s.

D. DeVorkin : Please comment on how the radio astronomers published technical instrumentation papers and papers dealing with scientific results.

W.T. Sullivan : Though they overlapped the generally published technical papers in radio journals, they published results in astronomical journals. Despite the recollections of some radio astronomers, there was little conflict or resistance to publishing radio data in astronomical journals.

A.B. Batten : Michael Ovenden often told me that the RAS Council held lengthy debates about whether or not Monthly Notices was a suitable journal for the publication of papers in radio astronomy.

W.T. Sullivan : Yes, there were such debates in the late 1940s, but with support from Ovenden, William McCrea, and others, by 1950 radio astronomers were definitely accepted by the Royal Astronomical Society.

D. Osterbrock : Conforming your statement that the optical astronomers welcomed the radio astronomers, and wanted their data, John Bolton, in his autobiographical article, told how when he first started at Caltech in 1956, Rudolph Mankowski came to see him in the first week, greeted him, and emphasized the need for accurate radio positions to identify the sources - and then came back at least once a week every week until he retired, to ask how the positions were coming!

F.K. Edmondson asked for a show of hands of those at the 1952 Rome GA.

(Some people)

\section{THE FIRST WOMEN APPOINTED TO IAU COMMISSIONS}

Barbara L. Welther, Smithsonian Astrophysical Observatory, Cambridge, USA

Seventy-five years ago at the meeting in Brussels in 1919, four commissions of the newly-formed IAU each proposed a women for membership. Subsequently, after the first meeting in Rome in 1922 , a few more women became members of commissions at each triennial meeting. The purpose of this paper is to examine how and why these particular women were invited to participate and what each contributed to her commission; also to 
examine whether any woman actually attended the first meeting in 1922 and, finally, how the participation of these pioneers influenced the acceptance of other women at subsequent meetings.

Of the four initial women, two were from Great Britain and two, from the United States. Fiammetta Worthington Wilson, Acting Director of the Meteor Section of the BAA, was named to Commission 22, and Mary Adela Blagg, a specialist in lunar nomenclature, Commission 17. Both women were elected Fellows of the RAS in 1916; but neither attended the first IAU meeting in 1922. Wilson died in 1920 and Blagg had Herbert Hall Turner of Oxford present her map of lunar formations at a special session in Rome.

The two women from the United States both worked on projects assigned by Edward Charles Pickering at the Harvard College Observatory. The research of Henrietta Swan Leavitt on photographic photometry was crucial to Commission 25. The head of that group was Frederick Seares at Mt. Wilson Observatory. He corresponded at length with Leavitt to resolve the differences between their systems for photographic magnitudes. However, before the issues could be resolved, Leavitt died in 1921. In her honor, Commission 25 published a brief tribute to her in the first volume of the Transactions.

Annie Jump Cannon was invited to participate on Commission 29. She had classified and was publishing the spectral types for over 225 thousands stars for the Henry Draper Catalogue. Uncertain whether she should attend the Rome meeting or not, she wrote to her friend at Oxford, Professor Turner, who encouraged her instead to sail to Peru and photograph spectra of southern stars for future research. Turner presumably wanted to spare Cannon the potential upset at the meeting of discussions to enhance the notation of the Harvard system. Although Cannon did not attend the first IAU meeting in Rome, in 1925 she travelled to England where she not only attended the second IAU meeting in Cambridge, but also received an honorary doctorate from Oxford University.

The second and third meetings included two women from France: Dorothea Klumpke Roberts joined Commission 28 in 1925 and subsequently published an atlas of nebulae in memory of her husband. And Gabrielle Camille Flammarion, who succeed her husband as director of Juvisy Observatory, joined Commission 16 for planetary studies in 1928. Also that year, two young Americans from Harvard College Observatory became members of commissions: Adelaide Ames and Cecilia Payne, both protégées of Harlow Shapley. The fourth and fifth meetings brought women from Denmark and Czechoslovakia: Julie Marie Vinter Hansen, renowned for her calculations and analysis of data for comets and minor planets, joined Commission 20 in 1932; and Mlle. B. Novàkovà, who had studied the rotation period of the solar chromosphere, joined Commission 10 in 1935.

In conclusion then, the women astronomers were all proposed for Commisions on the basis of their expertise. Although none of them attended the first meeting, at least four of them attended the second meeting and even more the third meeting in 1928. The Cambridge, (MA) meeting in 1932 drew a large number of women, some of whom were on commissions. And later that decade, women from several countries were participating in the IAU meetings. 
Discussion

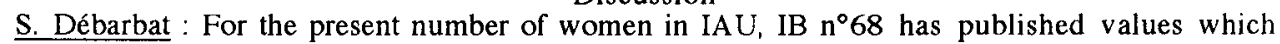
allowed to classify the countries according to the percentage of women among IAU members. At the beginning are, surprisingly, countries from latin origin located in the southern part of Europe followed by a group of anglo-saxon countries. At the end India and Japan

\section{A CALL FOR INDIRECT SOURCES TO SERVE FOR THE HISTORY OF THE IAU} Suzanne Débarbat, Observatoire de Paris, France

The history of the IAU produced by Adriaan Blaauw, has shown the difficulties he encountered for the very first years of the Union. From the oral tradition, at the Paris Observatory where I work from 1953, it was said that these IAU archives were in Belgium. After I passed this information to Adrian Blaauw he made an enquiry in the direction of our colleagues from the Royal Observatory in Brussels. Their answer was that there are no such archives in this Observatory ; it was also said that nobody there knows where they could be. For his research on the history of the IAU, Adrian Blaauw used archives, among other papers, from the Paris Observatory, recently available under the usual rules, from the time Benjamin Baillaud was the director of the Paris Observatory (1907-1929) ; they include the years of discussion and creation of the international unions after World War I.

A call is made to astronomers, historians of astronomy and any person related to this subject to look at any possibility in their home country to host archives related to the beginning of the IAU. Another call is made to any person related to astronomy to look in any archives and to check if they could contain documents concerning the IAU. But there are other possibilities to improve our knowledge about the IAU and its beginning ; it is possible to try to list some items on the subject : archives from people having played a rôle at the beginning of the Union; archives from persons of the same epoch who could have mentioned the subject; private papers or documents in hands of heirs of persons mentioned previously ; articles published in local magazines, newspapers, ... in towns or provinces from which these persons originate ; articles published in amateur or large public magazines ; biographies on given persons and generally speaking what is called grey litterature ;...

As a conclusion I would say that direct sources are important as well as indirect sources to contribute to the history of the IAU and I have a question : Do we have to propose a resolution on the search of archives in any observatory or astronomical institution to call attention of people on the subject and also on the importance of archives in any case ?

\section{A. Blaauw asks E. Müller (past GS) to speak on the subject.}

E. Müller : During my time as IAU General Secretary (1976-1979) it was decided that the IAU secretariat should have a permanent place rather than to have to move every three years to the place of the General Secretary. At that permanent place all IAU documents including all archives from the very first 